\title{
Who do treatments work for and why? Understanding treatment-effect mechanisms in stratified medicine
}

\author{
Richard Emsley ${ }^{1 *}$, Hanhua Liu', Sabine Landau², Graham Dunn \\ From 2nd Clinical Trials Methodology Conference: Methodology Matters \\ Edinburgh, UK. 18-19 November 2013
}

The development of stratified medicine depends on an understanding of treatment-effect mechanisms (effects on therapeutic targets that mediate the effect of the treatment on clinical outcomes). Yet the evaluation of these mechanisms is often absent from the design and analysis of studies for stratified medicine, and even if present, is subject to unmeasured confounding.

We review the problem of confounding (common causes) for the drawing of valid inferences concerning treatment-effect mechanisms, even when the data has been generated using a randomised controlled trial. We illustrate the potential of the predictive biomarker-stratified trial design, together with baseline measurement of all known prognostic markers, to enable us to evaluate both the utility of the predictive biomarker in such a stratification and to estimate how much of the treatment's effect is actually explained by changes in the putative mediator. We call this a biomarker-stratified efficacy and mechanisms evaluation (BS-EME) trial design.

The analysis strategy involves the use of instrumental variable estimation methods, using the treatment by predictive biomarker interaction as an instrumental variable together with adjustments for all know prognostic markers; the latter contributing to increased precision (as in a conventional analysis of treatment effects) rather than bias reduction. The analysis approach provides unbiased estimates even in the presence of unmeasured confounding.

We conclude that stratification without corresponding mechanisms evaluation lacks credibility and in the almost certain presence of mediator-outcome confounding, mechanisms evaluation is dependent on stratification for

${ }^{1}$ The University of Manchester, Manchester, UK

Full list of author information is available at the end of the article its validity. Our trial design and analysis approach evaluates both stratification and treatment-effect mediation.

\section{Authors' details}

'The University of Manchester, Manchester, UK. ${ }^{2}$ Institute of Psychiatry, King's College London, London, UK.

Published: 29 November 2013

doi:10.1186/1745-6215-14-S1-010

Cite this article as: Emsley et al.: Who do treatments work for and why? Understanding treatment-effect mechanisms in stratified medicine.

Trials 2013 14(Suppl 1):010.

Submit your next manuscript to BioMed Central and take full advantage of:

- Convenient online submission

- Thorough peer review

- No space constraints or color figure charges

- Immediate publication on acceptance

- Inclusion in PubMed, CAS, Scopus and Google Scholar

- Research which is freely available for redistribution

Submit your manuscript at www.biomedcentral.com/submit
() Biomed Central 